\title{
Pengembangan Pembelajaran Blended Learning Berbasis Website Di Program Studi Pendidikan Biologi Universitas Samudra
}

\author{
Ruhama Desy $M *$ dan Setyoko** \\ Program Studi Pendidikan Biologi, Universitas Samudra, Langsa, Aceh, Indonesia \\ *email: ruhamadesy@unsam.ac.id \\ **email: setyoko@unsam.ac.id
}

\begin{abstract}
The development of website based blended learning is aimed to promote change in the acceleration of learning process in higher education which is not bound by space and time, thus will directly improve the quality of learning process in the Study Program of Biology Education of University of Samudra. Utilization of information and communication technology in the development of website based blended learningin higher education combines face to faceand online.Research is functioned as learning mediation between lecturers and students of Study Program of Biology Education of University of Samudra. Research and Development was performed through the model of 4D with stages consisted of Define, Design, Developmentand Disseminatewhich were modified in accordance with the needof researcher. Subjects of experiment were students, lecturers, as well as information and communication technology experts. Instruments of study used were validation sheet and questionnaire. Analysis of qualitative data was done with stages of collecting data, reducing data, presenting data, and drawing conclusion. Result of research based on validation test showed that the validation of media expert was $82.65 \%$ with qualification of practical and did not need to be revised, the second validation of teaching expert obtained was $86.25 \%$ with qualification of highly practical and did not need to be revisedand validation of respondent by students obtained a value of $90.16 \%$ with qualification of highly practical and did not need to be revised. Based on the validation result, the development of website based blended learningis suitable to be used by the students of Biology Education of University of Samudra in learning which combines face to face learning at class and online.
\end{abstract}

Keywords: blended learning, learningdevelopment, website

\section{PENDAHULUAN}

Pembelajaran abad 21 di perguruan tinggi dengan perkembangan teknologi informasi dan komunikasi (TIK) yang sangat pesat, mendorong pembelajaran yang memanfaatkan sarana teknologi informasi dan komunikasi sebagai pendukung dalam pembelajaran. Ilmu pengetahuan dan teknologi terus menerus berkembang dengan pesatnya. Eksistensi Universitas Samudra sebagai Perguruan Tinggi Baru sudah pesat perkembangan dalam teknologi informasi dan komunikasi, yaitu tersedianya fasilitas internet bagi dosen dan mahasiswa. Asnawi (2015), fasilitas hotspotwifi dalam mengakses internet di Universitas Samudra antara lain beberapa titik; pada gedung fakultas Hukum hotspot, fakultas Keguruan dan Ilmu Pendidikan terdapat 2 titik hotspot yaitu FKIP hotspot dan Sejarah hotspot, fakultas Teknik terdapat 2 titik yaitu Teknik hotspot dan Unsam 3 hotspot, fakultas Pertanian dan Perpustakaan pusat terdapat 1 titik hotspot, fakultas Ekonomi 1 titik hotspot. Hotspot-wifi di Universitas Samudra dapat diakses diseluruh area kampus.

Akses hotspot-wifi ini sangat mendukung dosen maupun mahasiswa di Program Studi
Pendidikan Biologi dapat mengakses internet dimanapun diarea kampus, sehingga akan memperoleh informasi yang penting dalam materi penunjang perkuliahan. Fasilitas internet dapat dikembangkan sebagai sarana pembelajaran yang menunjang perkuliahan, dengan keterbatasan jam belajar dikelas dan materi yang disajikan dalam perkuliahan terlalu padat, sehingga pengembangan model pembelajaran dilakukan melalui blended learning. Blended learning merupakan pembelajaran yang semestinya diterapkan di perguruan tinggi (Norberget al., 2011; Jeffrey et al., 2014). Blended learning sebuah model pengajaran akibat dari keterbatasan waktu, tempat dan situasi, sehingga pembelajaran ini akan meningkatkan interaksi pembelajaran antara dosen dan mahasiswa (Kanuka et al., 2009; Jeffrey et al., 2014).

Blended learning bisa dilakukan dengan kombinasi tatap muka dikelas (face to face) dengan pembelajaran e-learning yang memanfaatkan media elektronik (Finn \& Bucceri, 2004; Akkoyunlu \& Soylu, 2008; Clark \& James, 2005; Vernadakis et al., 2011). Apalikasi eletronik yang dapat digunakan dalam pembelajaran melalui pembelajaran berbasis website, pembelajaran berbasis 
komputer, pembelajaran berbasis virtual dan kolaborasi digital (Nagarajan dan Wiselin, 2010). Perkembangan kurikulum KKNI di perguruan tinggi, pembelajaran lebih berpusat pada mahasiswa dengan memfokuskan pada capaian pembelajaran yang diharapkan. Proses pembelajaran yang mengutamakan pengembangan kreativitas, kapasitas, kepribadian, dan kebutuhan mahasiswa, serta mengembangkan kemandirian dalam mencari dan menemukan pengetahuan (Sailah et al., 2014). Pengembangan model pembelajaran blended learning akan mendorong percepatan informasi dan pengetahuan mahasiswa, sehingga akan meningkatkan pembelajaran yang efektif.

Pembelajaran yang efektif dapat membentuk susana pembelajaran mahasiswa yang aktif dan produktif (Fry et al., 2009). Pembelajaran di perguruan tinggi menuntut mahasiswa untuk aktif dalam mengembangkan materi yang diperoleh dari dosen pada saat tatap muka dan diluar perkuliahan. Pengembangan blended learning berbasis website menuntut pembelajaran tidak hanya terpusat pada jam perkuliahan dikelas, tetapi pembelajaran akan tetap berjalan diluar kelas dengan media online berbasis website. Perkembangan pembelajaran di era digital, seluruh aktivitas dan kegiatan pembelajaran di perguruan tinggi melibatkan electronic learning.Penelitian ini upaya untuk mendorong mahasiswa dalam student centered learning (SCL) melalui proses pembelajaran yang tidak terbatas oleh ruang dan waktu, sehingga dapat meningkatkan kualitas proses pembelajaran bagi mahasiswa Program Studi Pendidikan Biologi Universitasa Samudra.

\section{METODE PENELITIAN}

\section{Metode Penelitian}

Penelitian ini merupakan penelitian pengembangan (Research and Development). Metode pengembangan menggunakan model 4D; Define (pendefinisan), Design (Perancangan), Development (Pengembangan) dan Disseminate (Penyebarluasan) (Thiagarajan et al., 1974).

$$
\mathrm{A}_{\mathrm{i}}=\frac{\sum_{j=i}^{m} I}{m}
$$

Keterangan:

Ai : Rata-rata niali Indikator ke $i$

Iij : Rata-rata nilai Indikator ke $i$ kriteria $j$

$\mathrm{m}$ : Jumlah keseluruhan indikator

(Sumber: Amri \& Syuhendri, 2015)

\section{Rancangan Penelitian}

Rancangan penelitian ini menggunakan model 4D yaitu:

1. Tahap Pendefinisian

a. Melakukan analisis mahasiswa Program Studi Pendidikan Biologi Universitas Samudra.

b. Mengetahui karakteristik mahasiswa program studi pendidikan Biologi Universitas Samudra.

c. Mengeidentifkasi pengembangan blended learning berbasis website

d. Menyusun orientasi blended learning berbasis website.

e. Merangkum pembelajaran blended learning berbasis website.

2. Tahap Perancangan

a. Mendesain blended learning mengunakan website

b. Penyusunanmedia untuk mahasiswa dalam pencapaian kompetensi

c. Perancangan blended learning meliputi desain isiwebsite pembelajaran

d. Membuat pembelajaran blended learning dengan websitepembelajaran

3. Tahap Pengembangan

a. Validasi ahli dalam pengembangan pembelajaran blended learning berbasis website

b. Uji coba responden kepada mahasiswa dan dosen program studi Pendidikan Biologi Universitas Samudra

4. Tahap Penyebarluasan

Pengembangan pembelajaran blended learning berbasis website tidak disebarluaskan,hanya digunakanuntuk pembelajaran di Program Studi Pendidikan Biologi Universitas Samudra.

\section{Analisis Data}

Analisis data dengan deskriptif kualitatif dengan tahapan pengumpulan data, reduksi data, penyajian data dan penarikan kesimpulan. Data pengembangan pembelajaran blended learning berbasis website dilakukan berdasarkan hasil perolehan skor dari lembar validasi ahli dan uji coba responden mahasiswa. Rumus yang digunakan dalam uji validasi sebagai berikut:

$$
\mathrm{RTV}=\frac{\sum_{i=1}^{n} A i}{n}
$$

Keterangan:

RTV : Rata-rata hasil validasi

$\mathrm{Ai} \quad$ : Rata-rata nilai Indikator ke $i$

$\mathrm{N}$ : Jumlah Validator

(Sumber: Amri \& Syuhendri, 2015) 
Tabel 1. Indikator Tingkat Kevalidan

\begin{tabular}{cc}
\hline Rata-rata & Kategori \\
\hline $4 \leq \mathrm{RTV} \leq 5$ & Sangat Valid \\
$3 \leq \mathrm{RTV}<4$ & Valid \\
$2 \leq \mathrm{RTV}<3$ & Kurang Valid \\
$1 \leq \mathrm{RTV}<2$ & Tidak Valid \\
\hline
\end{tabular}

Tabel 2. Indikator Kualifikasi dan Kelayakan

\begin{tabular}{ccc}
\hline Rata (\%) & Kualifiaksi & Kelayakan \\
\hline $86-100$ & Sangat Praktis & Tidak Perlu Revisi \\
$76-85$ & Praktis & Tidak Perlu Revisi \\
$60-75$ & Cukup Praktis & Revisi \\
$<59$ & Kurang Praktis & Revisi \\
\hline \multicolumn{2}{l}{ (Sumber: Amri dan Syuhendri, 2015) }
\end{tabular}

\section{HASIL DAN PEMBAHASAN}

Hasil

Pengembangan pembelajaran blended learning berbasis website pada tahapan Pendefinisianberdasarkan analisis kebutuhan mahasiswa pendidikan Biologi Universitas Samudra Semester IV pada matakuliah Sistematika Hewan Vertebrata berjumlah 20 orang responden yaitu: (a) Mahasiswa memiliki perangkat Teknologi Informasi dan Komunikasi (TIK) terdiri dari Laptop, Notebook, Tablet dan Smartphone Android, (b) Mahasiswa dapat mengoperasikan perangkat TIK, dan mahasiswa lebih cenderungmengakses referensi di internet(c) Materi perkuliahan diperoleh dari makalah dan hasil diskusi tatap muka dikelas, sehingga diperlukan pembelajaran website untuk memfasilitasi pembelajaran secara online, (d) Ketersediaan Hotspot Wifi di Gedung Perkuliahan Program Studi Pendidikan Biologi Universitas Samudra sehingga pembelajaran dapat dilakukan melalui pengembangan website yang mudah digunakan untuk memberikan media pembelajaran bagi mahasiswa yang dapat mencakup group diskusi dan akses materi perkuliahan.

Tahapan Perancangan website yang dikembangkan dalam pembelajaran blended learningdisusun sesuai dengan kebutuhan mahasiswa untuk mencapai kompetensi dalam pembelajaran. Perancangan subtansi desain isi desain website: (a) Home, (b) Daftar Matakuliah, (c) Jadwal Perkuliahan; Ganjil dan Genap, (d) Materi Perkuliahan, (e) Tugas; Mandiri dan Kelompok, (f) Nilai; tugas, quiz, diskusi, mid semester dan ujian akhir semester, (g) Kontak Bantuan pengguna. Tahapan Pengembangan pembelajaran blended learning berbasis websitedilakukan uji validasi oleh ahli media website dengan hasil validasi $82,65 \%$ dengan kualifikasi Praktis dan tidak perlu untuk di revisi. Hasil rekapitulasi tingkat kevalidan disajikan dalam Tabel 3.

Tabel 3. Hasil RTV Validator Ahli Media

\begin{tabular}{lll}
\hline Indikator & Rata & Kategori \\
\hline Kecepatan (speed) & 3,3 & Valid \\
Homepage (layout) & 3,75 & Valid \\
Isi (konten) & 4 & Sangat Valid \\
Interaksi (friendly) & 3,3 & Valid \\
Kejelasan (readiblity) & 4 & Sangat Valid \\
Informasi (mobilitas) & 3 & Valid \\
Layanan (contac us) & 3 & Valid \\
\hline
\end{tabular}

Hasil masukan validasi ahli media website yang dikembangkan dengan menggunakan penambahan Hosting penyimpanan data kapasitas yang lebih besar dan menggunakan jasa penyedia layanan website yang lebih kompleksitas untuk pembelajaran mahasiswa secara online. Hasil masukan ditindak lanjuti dengan penggunaan hosting server $100 \mathrm{MB}$. Hasil uji validasi responden ahli pengajaran dilakukan terhadap Dosen Pendidikan Biologi, pada uji coba responden pertama diperoleh 75,14\% dengan kualifkasi Cukup Praktis dan harus dilakukan revisi. Hasil revisi yang dilakukan berdasarkan penambahan substansi isi website yang digunakan untuk pembelajaranmahasiswa yaitu: (a) Penambahan forum diskusi online yang bisa membentuk kelompok belajar dalam membahas materi yang sudah dipelajari pada tatap muka, (b) Penambahan isi konten akses materi perkuliahan dalam format microsoft word, power point, pdf dan video. Hasil validasi yang kedua setelah adanya perbaikan diperoleh 86,25\% dengan kualifikasi Sangat Praktis dan tidak Perlu di Revisi.Hasil rekapitulasi tingkat kevalidan disajikan dalam Tabel 4.

Tabel 4. Hasil RTV Validator Ahli Pengajaran

\begin{tabular}{lll}
\hline Indikator & Rata & Kategori \\
\hline Tampilan web & 3,3 & Valid \\
Isi Pembelajaran & 3,14 & Valid \\
Interaksi Link & 3,2 & Valid \\
\hline
\end{tabular}

Hasil uji coba responden oleh 20 orang mahasiswa dilakukan dengan memperoleh hasil 90,16\% kualifiasi sangat praktis dan tidak perlu direvisi. Tahapan Penyebarluasan dilakukan untuk dosen pendidikan biologi unversitas samudra dengan memberikan akun username dan password login ke dalam akun pengelolaan website. Mahasiswa diberikan informasi dalam pembelajaran dapat dilakukan melalaui alamat website. Hasil pengembangan pembelajaran blended learning berbasis website berdasarkan hasil skor uji validator dan saran. 


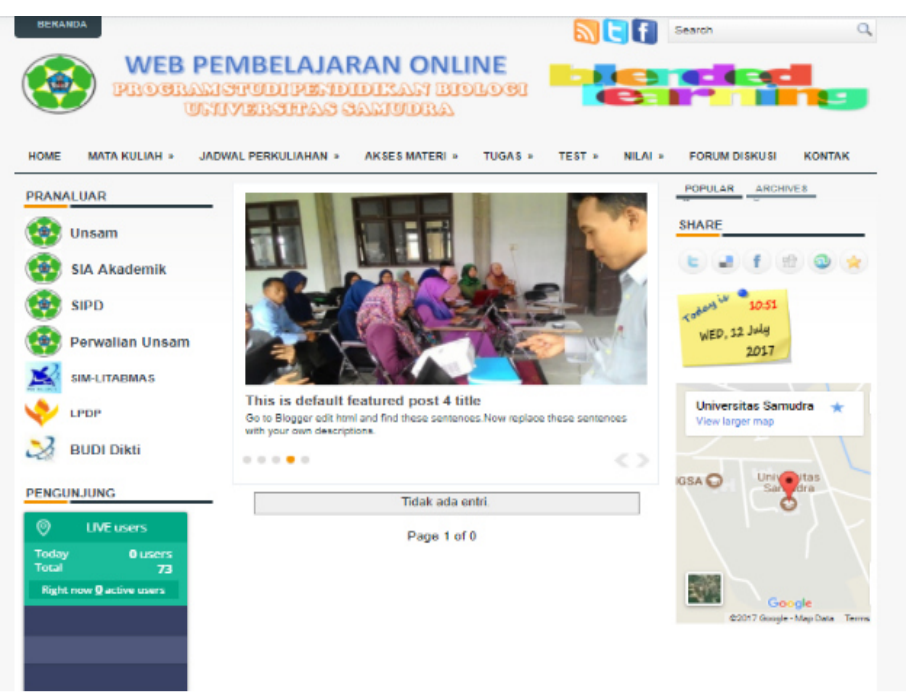

Gambar 1.Website Pembelajaran Blended Learning

\section{PEMBAHASAN}

Pengembangan pembelajaran blended learning berbasis website di Program Studi Pendidikan Biologi Universitas Samudra memberikan kemudahan belajarbagi mahasiswa dalam mencari sumber materi dan diksusi online dalam pembelajaran. Blended learning merupakan pembelajaran kombinasi tatap muka dikelas (face to face) dengan penggunaan website secara online. Blended learning merupakan penggabungan semua komponen yang dapat memberikan kemudahan dalam proses pembelajaran (Jeffrey et al., 2014).Pembelajaran face to face didalam kelas masih memiliki keterbatasan dalam waktu dan ruang, meskipun pembelajaran ini sudah sering dilakukan dengan ceramah yang diberikan dosen kepada mahasiswa dalam menyampaikan materi dan diskusi secara langsung dikelas.Hasil pengembangan yang dilakukan menunjukan bahwa pengembangan website dengan kualifikasi praktis dapat dipergunakan dalam pembelajaran berdasarkan validasi responden ahli media dan ahli pengajaran.Blended Learning program pembelajaran dimana lebih dari satu model transformasi pengetahuan yang dapat dilakukan untuk optimaliasasi pembelajaran. Prinsip dasar blended learning sebagai situasi dimana komunikasi tatap muka dan komunikasi onllineterintegrasi secara optimal sehingga, pengalaman belajar akan mencapai tujuan pendidikan (Singh dan Reed, 2001; Garrison dan Vaughn, 2008; Kistow, 2011).

Pembelajaran blended learning siap untuk diterapkan oleh mahasiswa karena tersedianya fasilitas hostpot wifi gratis di area gedung belajar program studi Pendidikan Biologi
Universitas Samudra. Pembelajaran ini akan mengintegrasikan tatap mukadalam pembelajaran online yang menggunakan sumber materipembelajaran dariinternet secara luas. Pelaksanaanblended learning berlangsung lebihbermakna karena keragaman sumber materi belajar yangdiperoleh oleh mahasiswa (Harding et al., 2005; Prasetioet al., 2012).Penggunaan internet untuk keperluan pembelajaran, dimana seluruh konten pembelajaran seperti; bahan ajar, grup diskusi, konsultasi, penugasan, dan ujian sepenuhnya disampaikan melalui website.Pengembangan websiteyang disesuaikan dengan kebutuhan pembelajar akan dapat membantu mahasiswa dalam mengunduh materi perkuliahan secara online, sehingga materi perkuliahan dapat disusun berdasarkan pemetaan materi yang dibuat di website pembelajaran (Arini, 2014; Prasetioet al., 2012).

Pembelajaran blended learningdapat diterapkan dengan perpaduan alokasi waktu dimulai $75 \%$ tatap muka untuk pembelajaran online dan $25 \%$ untuk pembelajaran secara online. Perbedaan kebutuhan ini dapat sesuai dengan karakteristik mahasiswa Pendidikan Biologi Universitas Samudra yang masih baru memulai dengan pembelajaran online, meskipun mahasiswa sudah sebagian besar memiliki perangkat teknologi informasi, diperlukan keterampilan dalam menggunakannya. Kebutuhan keterampilan penggunaanelectronic learning pada mahasiswa secara kolaboratif, interaktif dan efektif menggunakan teknologi informasi dan komunikasi dapat mengembangkan kemampuan belajarnya (Fulton, 1998; Mason, 2004; Birzina, et al., 2009). Efektivitas pembelajaran berbasi e-learningakan dapat meningkatkan 
prestasi belajar bagi mahasiswa (Noesgaard dan Rikke, 2015; Fathurohman, 2011).

\section{KESIMPULAN}

Pengembangan pembelajaran blended learning berbasis website layak digunakan oleh mahasiswa Pendidikan Biologi Universitas Samudra dalam pembelajaran yang memadukan antara pembelajaran tatap muka di kelas dengan online.Hal ini berdasarkan hasil uji validasi diperoleh validasi ahli media $82,65 \%$ kualifikasi praktis dan tidak perlu direvisi, validasi ahli pengajaran yang kedua diperoleh $86,25 \%$ kualifikasi sangat praktis dan tidak perlu direvisi dan validasi responden oleh mahasiswa diperoleh 90,16\% kualifikasi sangat praktis dan tidak perlu direvisi. Pengembangan website digunakan sebagai media pembelajaran dalam pembelajaran blended learning sehingga dapat meningkatkan kemandirian belajar yang mendorong pembelajaran terpusat pada mahasiswa yang tidak terbatas ruang dan waktu. Pengembangan ini masih terbatas untuk pembelajaran di Program Studi Pendidikan Biologi dan diperlukan penelitian lanjutan untuk mengetahu keefektifan pembelajaran blended learning berbasis website terhadap hasil belajar mahasiswa.

\section{UCAPAN TERIMAKASIH}

Ucapan terimakasih penulis haturkan kepada Direktorat Jendral Penguatan Riset dan Pengembangan Kemenristek Dikti, LPPM dan Universitas Samudra dan pihak terkait yang telah memberikan dana ataupun bantuan lainnya dalam penelitian ini.

\section{DAFTAR PUSTAKA}

Akkoyunlu dan Soylu. 2008. A Study of Students Perceptions in a Blended Learning Environmet Based on Different Learning Styles. Journal Educational Technology and Society, Vol 11 (1). 183-193.

Amri dan Syuhendri. 2015. Pengembangan Media Pembelajaran E-Learning Berbasis Web untuk Matakuliah Pendahuluan Fisika Inti. Jurnal Inovasi dan Pembelajran Fisika. Vol. 2. No. 1.

Arini, F. 2014. Pengembangan E-Stats Berbasis Web: Studi Kasus Universitas Negeri Semarang. Scientific Journal of Informatics, Vol. 1, No. 1

Asnawi. 2015. Sekilas Pengembangan Teknologi Informasi Dan Komunikasi Universitas Samudra,(Online),(http://www.unsam.ac.id/2015 /11/sekilas-pengembangan-teknologi-informasi- dan-komunikasi universitas-samudra.html), diakses 15 April 2016.

Birzina, R., Daiga, K., Jelena, J., dan Emilija, C. 2009. Effectiveness of interactive e-learning organization and quality assurance in European interuniversity master studies. Paper presented at the European Conference on Educational Research, University of Vienna, 28-30 September 2009.

Elaine, A., Jeff, S., dan Richard, G.. 2007. Blending In The Extent and Promise of Blended Education In The United States: Sloan-C.

Fathurohman, A. 2011. Pengaruh pengembangan model pembelajaran e-learning terhadap prestasi belajar mahasiswa fakultas kedokteran universitas muhammadiyah semarang. Jurnal tesis program pascasarjana magister teknik informatika UDINUS.

Fry, H., Steve, K., dan Stefphanie, M. 2009. The Handbook for Teaching and Learning in Higher Education. New York dan London: Routledge.

Jeffery, L. M., Jhon, M dan Gordon, S. 2014. Blended Learning: How Teacher Balance the Blend of Online and Calssroom Components. Journal of Information Technology Education, Vol 13. 121-140.

Kistow, B . 2011. Blended learning in higher education: A study of a graduate school of business, Trinidad and Tobago. Caribbean Teaching Scholar, Vol. 1, No. 2, 115-128

Nagarajan dan Wiselin. 2010. Online Educational System (E-Learning). International Journal Science dan Technology, Vol. 3 No. 4.

Noesgaard, S dan Rikke. 2015.The Effectiveness of E-Learning: An Explorative and Integrative Review of the Definitions, Methodologies and Factors that Promote e-Learning Effectiveness. The Electronic Journal of e- Learning Volume 13 Issue 4, (pp278-290)

Prasetio, P.M., et al. 2012. Perancangan dan Implementasi Content Pembelajaran Online dengan Metode Blended Learning.Jurnal Teknik Elektro Samratulangi. IPI 5752

Sailah, I., Tresna, D. K., I Made, S., SP Mursid., Endrotomo., Sylvi, D., Syamsul, A., Liliana S., Ludfi, D., Jumhur., Sri P., Lien, H., Henny, K., Emmy, H., Ridwan, R. T., Evawany dan Nafiron, M. 2014. Buku Kurikulum Pendidikan Tinggi. Jakarta: Direktorat Pembelajaran dan Kemahasiswaan, Direktorat Jendral Pendidikan Tinggi, Kementrian Pendidikan dan Kebudayaan

Thiagarajan, S., D. Semmel and M. I. Semmel. 1974. Instructional development for training teacher of Exceptional Children A Sourcebook. Bloomington Indiana: Indiana University.

Vernadakis, N., Maria, G., Vassiliki, D., dan Maria, M.. 2011. The Impact of Blended and Traditional Instruction in students Performance. Prosedia Technology (1). 439-44. 